\title{
Energy and thermal comfort performance evaluation of PCM ceiling panels for cooling a renovated office room
}

\author{
José Quesada Allerhand ${ }^{1 *}$, Ongun Berk Kazanci ${ }^{1}$, and Bjarne W. Olesen ${ }^{1}$ \\ ${ }^{1}$ International Centre for Indoor Environment and Energy, Department of Civil Engineering, Technical University of Denmark
}

\begin{abstract}
The performance of suspended ceiling panels with phase change materials (PCM) for comfort cooling applications in office rooms was studied. The panel consisted of a metal casing, which encapsulates the PCM. Water can circulate through the pipes embedded in the panel to influence the latent energy storage of the material. To evaluate the performance of the PCM panels, a comparison with an all-air system and a thermally active building system (TABS) was made. Using TRNSYS 17, a recently renovated room in the Technical University of Denmark was modelled. The room was simulated during the cooling season with each of the three cooling systems in which the thermal environment and the corresponding energy use were determined. Operative temperature was maintained between $22^{\circ} \mathrm{C}$ to $27^{\circ} \mathrm{C}$ at least $90 \%$ of the occupied period with each system. Similarities were observed between the PCM and TABS systems. Energy savings of $15 \%$ and peak cooling power reduction of $30 \%$ compared with the all-air system were observed. This study proved the common claim that PCM ceiling panels and TABS perform similar in terms of the created thermal indoor environment and energy savings, as well in terms of heat removal from the indoor space. Therefore, PCM ceiling panels could be used as an alternative for TABS in renovation projects while providing similar benefits to TABS.
\end{abstract}

\section{Introduction}

Concerns over climate change have caused a big interest in improving building energy efficiency and reducing building related greenhouse gas emissions [1]. In recent years, there has been a focus on minimizing heat gains and losses to and from buildings, by means of improvements in building envelopes, particularly in cold and mild climates. In the next century however, cooling related energy use will increase due to economic development, increase of population, and climate change. In countries with cold and mild climates, the focus on heat preservation can lead to the increase of the cooling demand [2]. Worldwide, the demand for space cooling is expected to triple between 2010 and 2050 [3] .

An interesting method for cooling buildings is by activating the thermal mass of multistory buildings by circulating cold water in their slabs. This method has been defined as "Thermally Active Building Systems" or TABS. One of the most important benefits of these systems, is that they can provide thermal comfort operating with water temperatures close to the desired room temperatures. This characteristic allows these systems to be able to use renewable energy as sources, or increase the efficiency of heat pumps, thus, reducing the demand for fossil fuels and the building's greenhouse gas emissions[4][5].Evidently, TABS have to be incorporated in the building from the design stage. This makes TABS an unfeasible solution for existing buildings that were designed with other room-conditioning systems. In this context, a lot of attention has recently been given into phase change materials (PCM). Significant research has been done in the use of these materials as a way to improve thermal comfort in buildings and achieve energy savings [6][7][8][9][10]. PCM's are materials that are engineered to change phase (from solid to liquid for example) at a desired temperature range, depending on the application. Thermal energy can be stored or released in the material at a narrow temperature range as molecular bonds form or break during the phase change. This means that a similar effect as a building with a high thermal mass can be achieved with considerably less material [11].

In this work, the performance of a ceiling panel with PCM during the cooling season of Denmark was assessed. The main objective was to show that the use of the panel in office rooms can result in the same benefits as TABS in terms of thermal comfort and energy performance. This implies that buildings that were not originally designed with TABS can still benefit from the environmental and comfort benefits through the use of the PCM system.

\section{Methodology}

The PCM ceiling panel's performance was assessed by simulating the thermal indoor environment and comparing the energy use of the PCM system against an all-air system and a TABS system using the same boundary conditions. A methodology similar to the one employed in [12] was used for this purpose. The

* Corresponding author: joqal @byg.dtu.dk 
simulations were performed using TRNSYS 17 [13].

\subsection{Simulation conditions}

\subsubsection{Room}

An existing room in the Technical University of Denmark was modelled in TRNSYS 17. The room has a suspended ceiling of $60 \mathrm{~cm}$ x $60 \mathrm{~cm}$ gypsum panels. Some panels are used to fix luminaires, air terminal devices, alarms and sensors. Behind the suspended ceiling there is a plenum space of $0.5 \mathrm{~m}$. The layout of the room is shown in

Fig. 1, while the room's properties are shown in Table 1. The room's west wall is an external wall. This wall has two layers of brick with no insulation between them. The glazing elements are two pane windows. The considered U-Value of the wall was $2.3 \mathrm{~W} / \mathrm{m}^{2} \mathrm{~K}$ while the considered properties of the window were 2.8/0.75/0.82 (U/g/LT).

Table 1. Room geometric parameters and heat gains

\begin{tabular}{|l|c|c|}
\hline Orientation & West & \\
\hline Height & 2.9 & $\mathrm{~m}$ \\
\hline Length & 8.8 & $\mathrm{~m}$ \\
\hline Width & 5.8 & $\mathrm{~m}$ \\
\hline Plenum height & 0.5 & $\mathrm{~m}$ \\
\hline Area & 51 & $\mathrm{~m}^{2}$ \\
\hline Volume & 148 & $\mathrm{~m}^{3}$ \\
\hline Total window area & 7.4 & $\mathrm{~m}^{2}$ \\
\hline Occupant gains & 35 & $\mathrm{~W} / \mathrm{m}^{2}$ \\
\hline Equipment gains & 32 & $\mathrm{~W} / \mathrm{m}^{2}$ \\
\hline Lighting & 10 & $\mathrm{~W} / \mathrm{m}^{2}$ \\
\hline $\begin{array}{l}\text { Total internal heat } \\
\text { gains }\end{array}$ & 77 & $\mathrm{~W} / \mathrm{m}^{2}$ \\
\hline
\end{tabular}

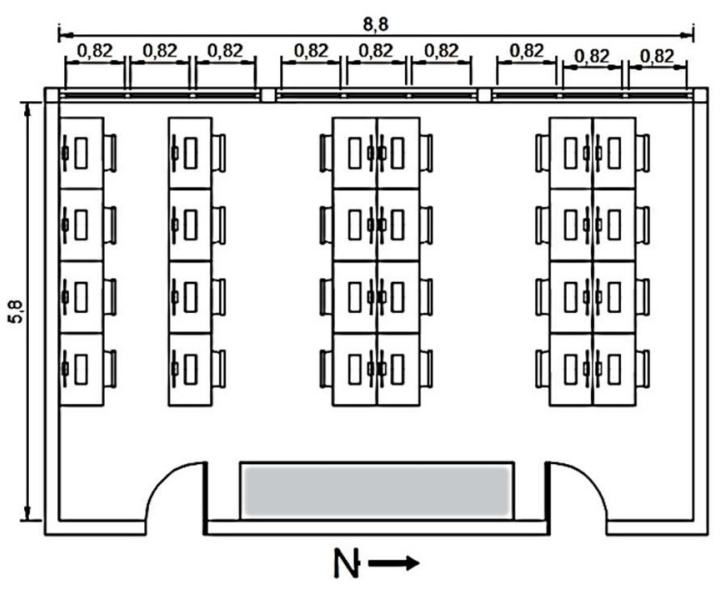

Fig. 1. Room Layout (units in $\mathrm{m}$ ).

\subsubsection{Weather and simulation period}

A TMY-2 weather file for Copenhagen was used for the simulations. The selected simulation period was from April 30 to October 01. The cooling and heating demand to maintain the room operative temperature between 20 and $26^{\circ} \mathrm{C}$ is shown in Fig 2. The maximum cooling demand is $65 \mathrm{~W} / \mathrm{m}^{2}$.

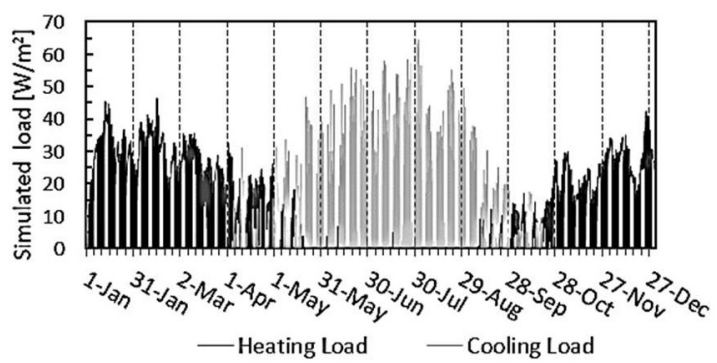

Fig 2. Simulated room heating and cooling demand.

\subsubsection{Internal Gains}

Occupants, plug load, and lighting internal gains were considered in the simulations. 24 work stations were considered in the room. Each work station considers an occupant, a desktop computer and a laptop computer. The occupant activity was assumed to be 1.2 met. Values of $50 \mathrm{~W}$ were assumed for desktop computers. Laptop gains of $18 \mathrm{~W}$ were considered following the work in [14]. The heat gains from the lighting fixtures was assumed as $10 \mathrm{~W} / \mathrm{m}^{2}$. The occupancy schedule was considered from 8:00 to 17:00 with a mid-day break [15].

\subsection{Thermal environment assessment}

The thermal environment assessment was performed with the operative temperature classification suggested in prEN 16798 [15]. The indoor environment was studied to determine the capacity of each system to create comfort conditions. The initial aim was to achieve $90 \%$ of occupied time within Cat.II, which meant the operative temperature had to be kept between $23^{\circ} \mathrm{C}$ and $26^{\circ} \mathrm{C}$. The indoor environment was also assessed to have a reference for the energy use comparison.

\subsection{Energy performance assessment}

The three compared systems were assessed in terms of their primary energy use. Two energy intensive processes were considered. The first process is the conditioning of the outside air done by an air handling unit. All the compared systems use this process. The second process is the cooling of the water circulated in 
the TABS and PCM ceiling panels. The all-air system does not consider this process. The processes are shown in Fig. 3. And Fig. 4.

Fig. 3. shows the air conditioning process. The considered energy use is the energy used by supply and exhaust fans, energy used by a pump to circulate the cooling coil water, and the energy that a heat pump uses to cool down the water that will go in the cooling coil. Electricity is the primary energy source for all of the components.

Fig. 4. shows the process considered for the energy calculations of the water circuits of the TABS and PCM system. The energy used considered in this case is the energy from a pump which circulates the water into the slab or panels and the energy that a heat pump uses to cool down this water. A primary energy factor of 1.8 was considered according to Danish building regulation BR-2020 [16]. The coefficient of performance (COP) of the heat pump varies from 1.5 to 5.5 depending on the operating conditions. The power of the water pump varies from $20 \mathrm{~W}$ to $50 \mathrm{~W}$, as a function of the flow rate. In both cases, the values are based on information from commercially available products.

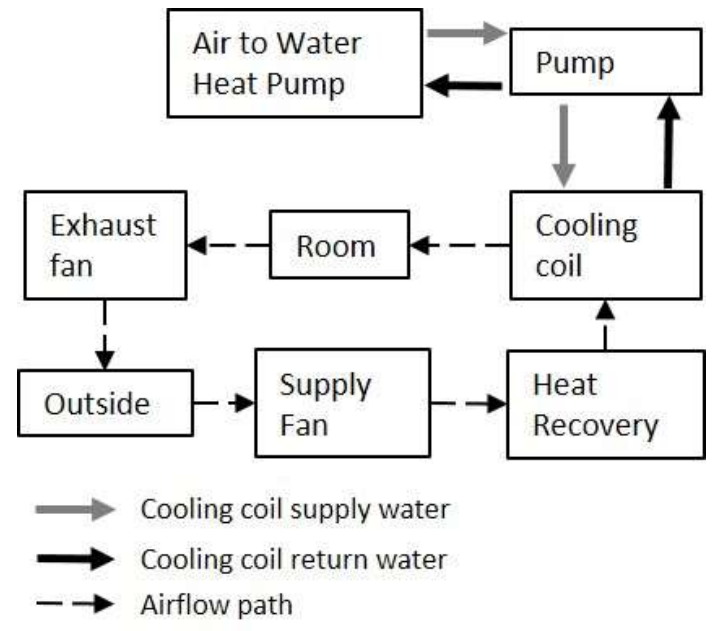

Fig. 3. Air conditioning process considered in the energy use calculations

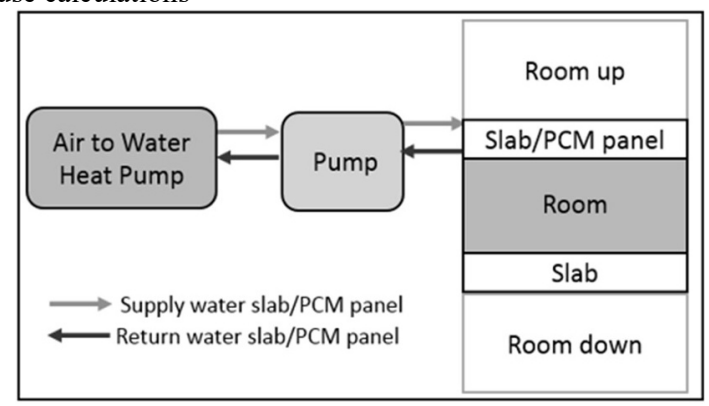

Fig. 4. Water loop process for TABS and PCM in energy use calculations

\subsection{HVAC systems description}

The different system set points were determined by a combination of steady state calculations and dynamic simulations. Dynamic simulations in TRNSYS were used to optimize the water circulation schedule and water supply temperature of the PCM and TABS systems. Table 4 shows the final operation conditions of the different systems.

\subsubsection{All-air system}

The all-air system is a convective system that uses conditioned outdoor air to provide comfort conditions in the room. The system uses a variable air volume strategy that depends on the room operative temperature and the outside temperature. The airflow varies between a minimum value of $3.7 \mathrm{ACH}$ to provide acceptable air quality as long as the room's temperature is below $23^{\circ} \mathrm{C}$ and a maximum value of 8.5 ACH when the room's temperature is above $26^{\circ} \mathrm{C}$. The supply air temperature set point varies from $18^{\circ} \mathrm{C}$ when the outdoor temperature is higher than $26^{\circ} \mathrm{C}$ to $20^{\circ} \mathrm{C}$ when the outdoor temperature is lower than $18^{\circ} \mathrm{C}$. The outdoor air is directly used and not conditioned as long as the room's temperature is below $26^{\circ} \mathrm{C}$. There is no active heating of the supply air; however, there is a heat recovery unit. The outdoor air is able to bypass the heat recovery, which will activate if the room's operative temperature is lower than 23 ${ }^{\circ} \mathrm{C}$ and the exhaust air temperature is higher than the outdoor air temperature, or when the outdoor temperature is less than $18{ }^{\circ} \mathrm{C}$ and the exhaust air temperature is higher than the outdoor air temperature.

\subsubsection{TABS}

The thermally active building system (TABS) provides cooling by circulation of water through the building's slabs. Ventilation is provided mechanically with an air handling unit. The ventilation system operates at a constant air volume to satisfy the required ventilation rate. Heating is provided passively by a heat recovery unit, as in the case of the all-air system.

The TABS was modelled based on the construction shown in Fig5. The TABS structure consist of a layer of screed, acoustical insulation, and concrete, the thermal properties of the materials are shown in Table 2 . The pipes that circulate water are embedded in the middle of the concrete layer to activate its thermal mass. A similar structure to a TABS system studied by [17] was used. 


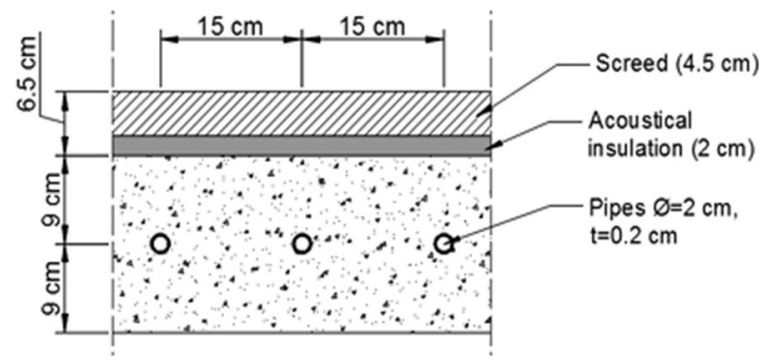

Fig. 5. TABS slab structure

Table 2. TABS materials properties

\begin{tabular}{|l|c|c|c|}
\hline & $\begin{array}{c}\text { Specific } \\
\text { Heat }\end{array}$ & Density & $\begin{array}{c}\text { Thermal } \\
\text { conductivity }\end{array}$ \\
\hline$[\mathrm{J} / \mathrm{kgK}]$ & {$\left[\mathrm{kg} / \mathrm{m}^{3}\right]$} & {$[\mathrm{W} / \mathrm{mK}]$} \\
\hline Screed & 1.008 & 2000 & 1.4 \\
\hline $\begin{array}{l}\text { Acoustic } \\
\text { insulation }\end{array}$ & 1.512 & 50 & 0.04 \\
\hline Concrete & 1.008 & 2400 & 2.1 \\
\hline
\end{tabular}

\subsubsection{Phase change material (PCM)}

A commercially available PCM (Rubitherm R24) is poured into a steel casing, which works as a panel which is then installed in the suspended ceiling of the room. The panels are $60 \mathrm{~cm} \mathrm{x} 60 \mathrm{~cm}$ and have a total thickness of $3 \mathrm{~cm}$. The panels contain copper pipes for water circulation. The pipes are incorporated into an aluminum structure that provides stability and could potentially improve the heat transfer of the panel. The working principle is that the PCM will store the heat gains during the day as it melts. After the occupants leave the room, cool water circulates in the PCM to discharge the stored energy and solidify the PCM, so that the panel can absorb the heat gains of the following day. Table 3 shows a summary of the main material properties obtained from the manufacturer [18].
Table 3. Properties of the PCM used

\begin{tabular}{|l|l|l|}
\hline Melting Range & $21-25$ & ${ }^{\circ} \mathrm{C}$ \\
\hline Freezing range & $25-21$ & ${ }^{\circ} \mathrm{C}$ \\
\hline Heat storage capacity & 160 & $\mathrm{~kJ} / \mathrm{kg}$ \\
\hline Specific heat capacity & 2 & $\mathrm{~kJ} / \mathrm{kgK}$ \\
\hline Density solid & 880 & $\mathrm{~kg} / \mathrm{m}^{3}$ \\
\hline Density liquid & 770 & $\mathrm{~kg} / \mathrm{m}^{3}$ \\
\hline Heat conductivity & 0.2 & $\mathrm{~W} / \mathrm{mK}$ \\
\hline
\end{tabular}

The PCM system consist of the incorporation of the ceiling panels with PCM in the room. Just as in the case of TABS, fresh air is provided with mechanical ventilation at a constant air volume. Water is circulated during the night to discharge the PCM as shown in Fig.4. The amount of PCM that was used for the system was decided by considering the real boundary conditions of the room and the panel. Regarding the room, $50 \%$ of the ceiling area was selected to install PCM panels based on the room's actual ceiling. In a thickness of $2 \mathrm{~cm}$, and $50 \%$ ceiling coverage, $40 \mathrm{~W} / \mathrm{m}^{2}$ can be stored in the PCM, the rest of the cooling load will be removed by the mechanical ventilation. In the simulation model, an overall conductivity of $1.2 \mathrm{~W} / \mathrm{mK}$ was assumed, to account for the aluminum components of the panel. This assumption was based on a different study, in which this overall thermal conductivity was measured in a similar panel to the one used in this study [7].

To model the PCM panel, TRNSYS component type 399 was used. This is a validated component which simulates PCM in wall constructions embedded with pipes[19]. The PCM panel was modelled as a single layer of PCM in the component. The density of the PCM used was the average between the density of the liquid and the solid states $\left(825 \mathrm{~kg} / \mathrm{m}^{3}\right)$. The melting and freezing curves provided by the manufacturer were used for the enthalpy-temperature functions required as input for Type 399 [18] [19]. Table 4 shows a summary of the operation conditions of the three tested climatic systems.

Table 4. Set points for the compared systems.

\begin{tabular}{|c|c|c|c|c|c|c|c|}
\hline & Fan sched. & $\begin{array}{c}\text { Min. air } \\
\text { flow }\end{array}$ & $\begin{array}{c}\text { Max. air } \\
\text { flow }\end{array}$ & $\begin{array}{c}\text { Supply air } \\
\text { temp. }\end{array}$ & $\begin{array}{c}\text { Water supply } \\
\text { temp. }\end{array}$ & $\begin{array}{c}\text { Water } \\
\text { flow rate }\end{array}$ & $\begin{array}{c}\text { Water } \\
\text { circulation } \\
\text { sched. }\end{array}$ \\
\hline $\begin{array}{c}\text { All- } \\
\text { Air }\end{array}$ & $08: 00-17: 00$ & $3.7 \mathrm{ACH}$ & $8.5 \mathrm{ACH}$ & Variable & - & - & - \\
\hline TABS & $08: 00-17: 00$ & $3.7 \mathrm{ACH}$ & - & $22^{\circ} \mathrm{C}$ & $19^{\circ} \mathrm{C}$ & $326 \mathrm{~kg} / \mathrm{h}$ & $22: 00-05: 00$ \\
\hline PCM & $08: 00-17: 00$ & $3.7 \mathrm{ACH}$ & - & $20^{\circ} \mathrm{C}$ & $18^{\circ} \mathrm{C}$ & $326 \mathrm{~kg} / \mathrm{h}$ & $17: 00-05: 00$ \\
\hline
\end{tabular}




\section{Results}

Fig.6 shows the classification of the thermal environment of the room during the cooling season for the three different modelled systems. The room had the largest percentage of occupied time within Cat.II with all-air system $(85 \%)$, followed by TABS $(81 \%)$ and the PCM system (73\%). All systems were able to provide at least $90 \%$ of occupied time within C. III.

Fig.7 shows the energy use of the different climatic systems during the cooling season. The all-air system has the largest energy use $\left(18.8 \mathrm{kWh} / \mathrm{m}^{2}\right)$ followed by PCM (16.1 $\left.\mathrm{kWh} / \mathrm{m}^{2}\right)$ and TABS (16 $\mathrm{kWh} / \mathrm{m}^{2}$ ). The energy savings of TABS and PCM relative to all-air system were $15 \%$ and $14 \%$, respectively. Electricity from the fans was the largest contributor to energy use for all systems. Most of the total saving relative to all-air system comes from the electricity used by fans and pumps.

Fig. 8 shows the percentage of heat removed by the floor, ceiling and the air of the ventilation system during the cooling season. The all-air system, $70 \%$ of the heat is removed by the ventilation system while in TABS And PCM systems at least $50 \%$ of the heat is removed by the active surfaces.

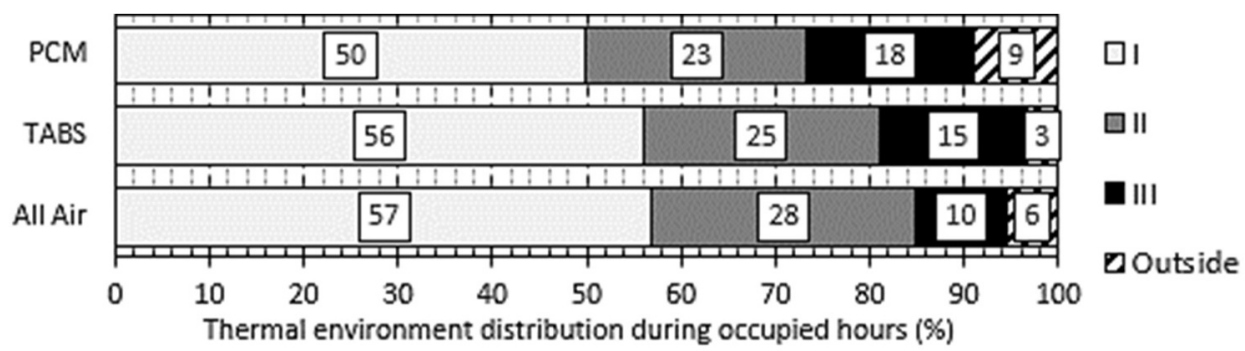

Fig. 6: Room thermal environment classification under the tested climatic systems

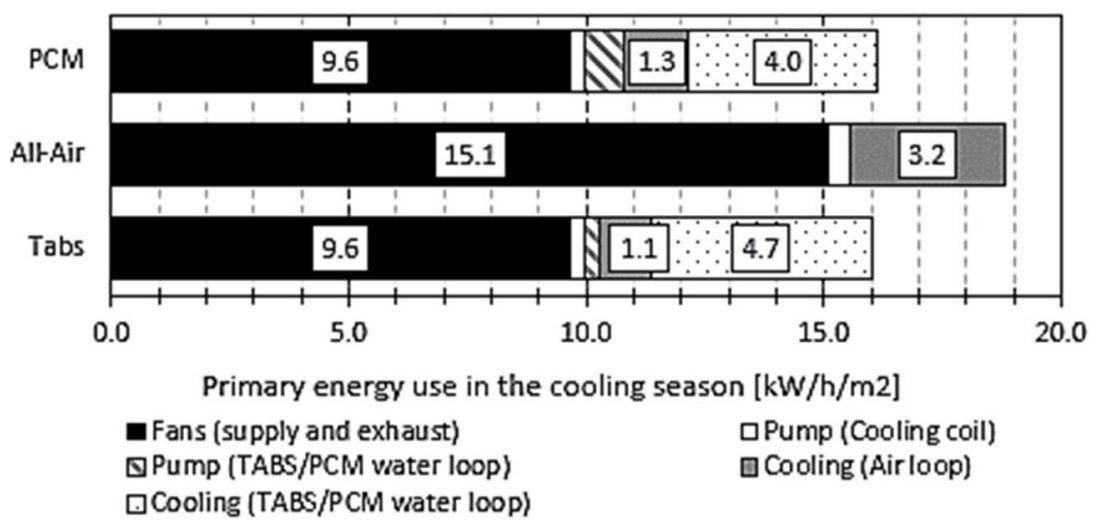

Fig. 7. Room energy use under the tested climatic systems.

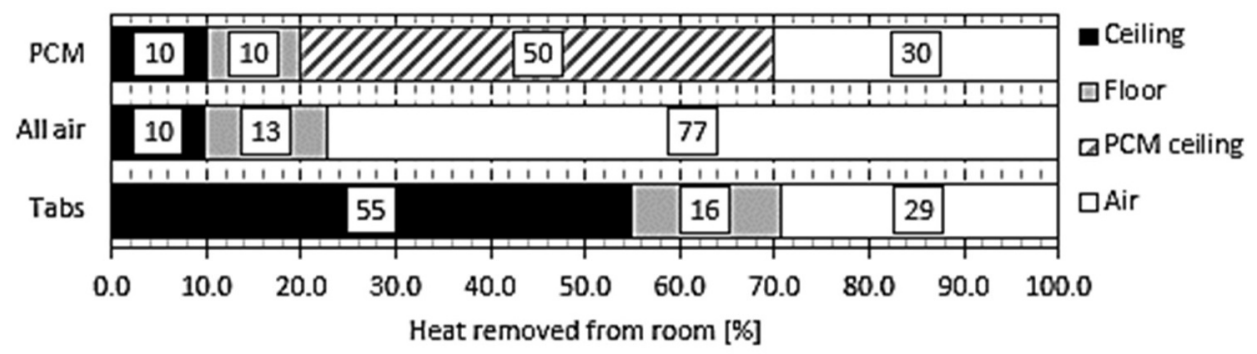

Fig. 8. Heat removed from the room during the cooling season. 
Fig.9 shows the frequency distribution of the room's operative temperature during the occupied period. Temperatures above $26^{\circ} \mathrm{C}$ are observed with all systems. Temperatures above $27^{\circ} \mathrm{C}$ are observed in TABS and PCM. Temperatures below $23^{\circ} \mathrm{C}$ are observed in all systems. The temperatures in the air system are in a narrower range than the temperatures of the other two systems, which match with experience with radiant systems.

In Fig. 10 the specific cooling power of the systems are shown for a summer day (July $\left.10^{\text {th }}\right)$. In the all-air system, the peak heat removal
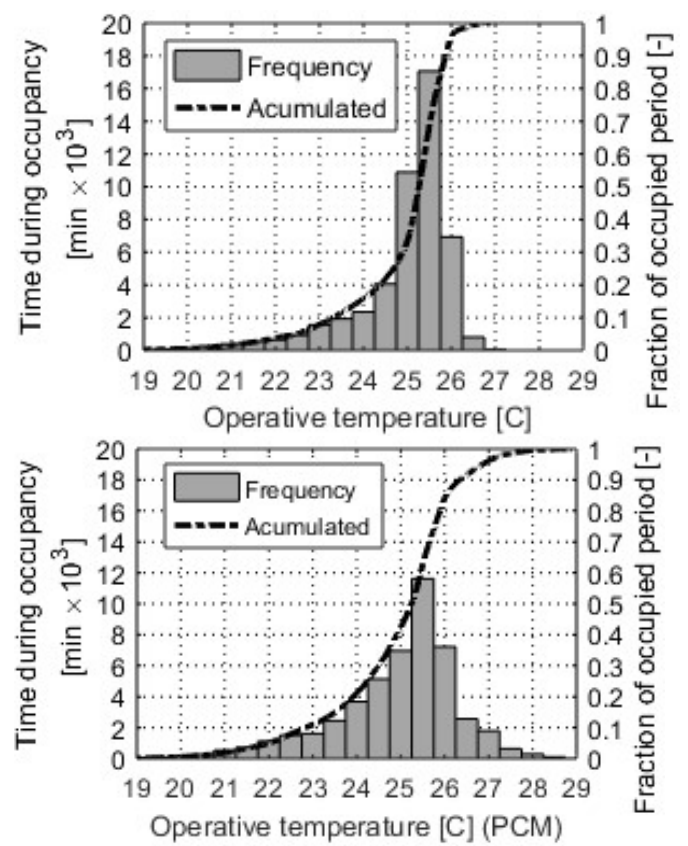

Fig 9. Room operative temperature frequency distribution during occupied hours of the different tested systems
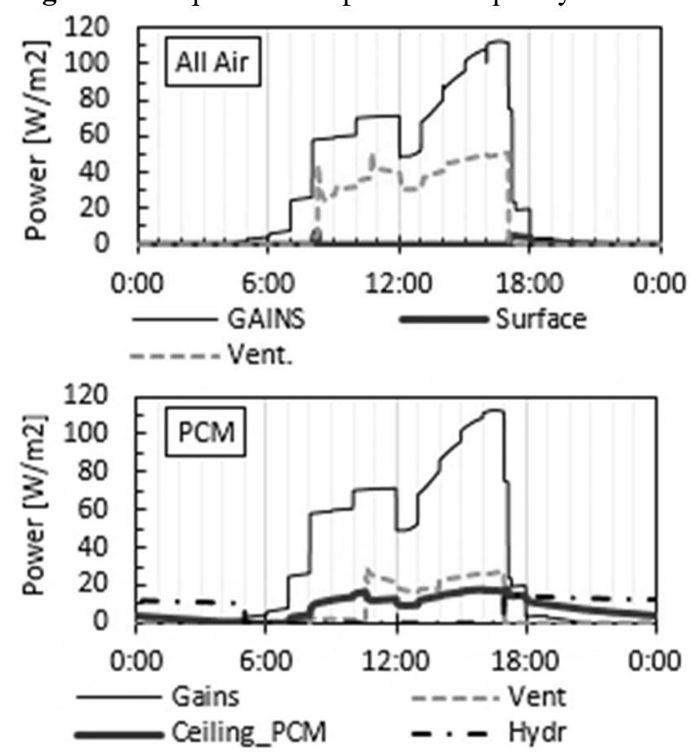

Fig 10. Cooling power of the simulated systems during a summer day (July $\left.10^{\text {th }}\right)$ (cooling power) achieved by the ventilation is 50 $\mathrm{W} / \mathrm{m}^{2}$. In the case of the TABS system the peak cooling power of the ventilation is $30 \mathrm{~W} / \mathrm{m}^{2}$ and the peak cooling power of the active surfaces (ceiling and floor) is $40 \mathrm{~W} / \mathrm{m}^{2}$. In the PCM system, the peak cooling power from the ventilation is again $30 \mathrm{~W} / \mathrm{m}^{2}$ and the peak cooling power of the PCM ceiling is 20 $\mathrm{W} / \mathrm{m}^{2}$. In both TABS and PCM, a reduction of $30 \%$ in the peak cooling power of the ventilation was observed.

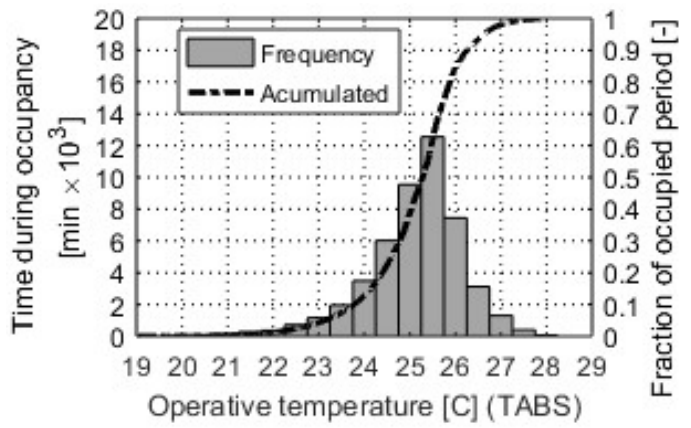




\section{Discussion}

The original design goal of $90 \%$ occupied time within Cat.II was not obtained with any of the systems. The original design criteria was not met due to a combination between the systems functioning, the simulated weather and the building. All of the systems resulted in more than $90 \%$ of occupied hours within Cat.III. This was considered sufficient to make a comparison of energy savings between the systems. Observing the operative temperature frequency distribution from Fig.9, cold temperatures play a major influence in the thermal discomfort in the room. This result is not entirely unexpected, due to the combination of three factors. First, the cooling season includes the months of May and September, which have a mixed cooling and heating demand. Second, the room's envelope has high U-values and third, no active heating measures were provided.

The PCM thermal comfort performance proved to be not as effective as expected. In terms of thermal comfort, its performance was below the other two systems; however, slightly. If the comfort criteria is relaxed into Cat.III, the PCM performance is much closer to the other systems, more than $90 \%$ of the occupied period is maintained in this category during the cooling season by all systems. An important observation is that these results were achieved only by increasing the thermal conductivity of the PCM to 1.2 $\mathrm{W} / \mathrm{mK}$. This represented an enhancement of the thermal conductivity in the panel and the value is based on the findings of a similar study performed by [7].

The all-air system was the system with the highest energy use during the simulation period. The energy use performance of PCM system and TABS were similar. Energy savings of $15 \%$ and $14 \%$ were found by the TABS and PCM systems, respectively, relative to the all-air system. The energy savings were mostly caused by the energy savings in the fan. An energy saving from the fans of the PCM and TABS systems was expected when compared with the all-air system, as the maximum airflow rate of these systems is considerably lower than that of the all-air system. The energy use for cooling (water and air) is higher in the case of TABS and PCM compared with the all-air system. This might be happening because the VAV system has more opportunity to use free cooling from the outdoor air. This finding matches with the findings of [9].

Other authors have reported energy savings from $16 \%$ to almost $60 \%$ when comparing radiant systems with all-air systems. Almost all of these authors acknowledge that the climate and building type have a big influence in the savings found, [17],[12],[20]. The study performed in [17] found 16\% energy use savings in a moderate climate, which is a similar result as found in this study.

Both TABS and the PCM system remove at least 50\% of the heat from the room through the active surfaces, behaving as radiant systems. The ventilation system removed $30 \%$ of heat in both systems, and the remaining $70 \%$ was removed by the surfaces. In the case of PCM, the ceiling surface with the PCM removed most of the heat, and that the ceiling surface without PCM stored less heat, as expected. Of the heat removed by surfaces in the TABS system, the ceiling removes most of the heat as expected.

In Fig. 10 the cooling power of the ventilation and surfaces of the different systems during 24 hours was shown. Both PCM and TABS managed to reduce the peak cooling power with respect to the all-air system by compensating with cooling by the surfaces and shifting some of the cooling load in the night, as can be seen by the hydronic cooling power curves. TABS and PCM reduced the peak power during the day from around $45 \mathrm{~W} / \mathrm{m}^{2}$ to $30 \mathrm{~W} / \mathrm{m}^{2}$, which is a $33 \%$ reduction in peak cooling power. Another study found reduction in peak cooling powers of $27 \%$ when comparing radiant systems to all-air systems [20]. The cooling power of the PCM ceiling was between 15 and 20 $\mathrm{W} / \mathrm{m}^{2}$. Measurements performed on PCM ceiling panels installed in the ceiling of a room in [21] found cooling powers of $10 \mathrm{~W} / \mathrm{m}^{2}$ to $15 \mathrm{~W} / \mathrm{m}^{2}$.

Fig 10. suggests that the building and weather have a large influence in the total heat removed. The cooling power curve for the all-air system was expected to be closer to the gains curve. This is evidence that a considerable amount of heat is being transmitted or stored in the walls. It is likely that heat is being transmitted to the outside, the envelope's transmission is expected to be high as the outer wall has a U-Value of $2.3 \mathrm{~W} / \mathrm{m}^{2} \mathrm{~K}$ and the window has a U-value of 2.8 $\mathrm{W} / \mathrm{m}^{2} \mathrm{~K}$. It is expected that the outdoor temperature can be lower than the indoor temperature even during the day, so it is reasonable to assume that considerable heat transfer from the room to the outside by transmission is a possibility.

The results should be used with caution as no experimental measurements were performed to validate the models. A critical assumption that was made and remains to be tested is the thermal conductivity increase considered in the panels. Further work is needed to determine precisely this value. However, results are in good agreement with similar studies, which is a good indication of the validity of these results.

Although the PCM component was not validated in this study, other authors have studied the component in detail. Some of the limitations of Type 399 are explained in [22] based on a numerical validation 
performed. The authors mention that Type 399 can fail to detect phase change events if large simulation time steps are used. This is because of the implicit numerical method used in the component. The authors observed that under time steps of 1 minute, the issue was minimized. Other issue Type 399 has is that it is not able to model super cooling in the PCM. This could lead to an over estimation of the heat capacity during the solidification process of the PCM. These limitations were minimized by using 1 minute time steps in the simulations; however, there are no other developed PCM components that are able to simulate embedded pipes for water circulation in the structure in TRNSYS. This situation highlights the importance of performing a field test or full scale experiment to have more confidence in the results and expand the use of the models.

Finally, to fully determine if the results are being caused by the PCM and not other factors, a similar study performed under different climates, occupant loads, and building characteristics is needed. It is also important to study the indoor environment and energy use of the system during the whole year to assess the effect of the PCM during the heating season.

\section{Conclusion}

This study proved that the tested PCM ceiling panel concept can be potentially used in building retrofit projects to create similar benefits to TABS as similar performance and behavior of the systems were observed. The PCM system achieved the same energy savings $(15 \%)$ and peak cooling power reduction $(30 \%)$ as $\mathrm{TABS}$, when compared to a convective system while maintaining similar indoor thermal comfort conditions, proving that PCM panels work similar to TABS. It is possible to shift some of the cooling demand into the night, which may lead to renewable energy sources utilization strategies, such as night ventilation cooling or night radiative cooling. Additionally, the system operated at temperatures considered adequate for high temperature cooling. The indoor environment is also indirectly benefited, as less air needs to be supplied into the room, reducing the draught risk.

This study was financially supported by the European Union's Horizon 2020 research and innovation programme under grant agreement No. 723649 and by the International Centre for Indoor Environment and Energy (ICIEE), Technical University of Denmark (DTU).

\section{References}

[1] X. Cao, X. Dai, and J. Liu, Energy Build., 128,198-213, (2016).

[2] K. J. Lomas, S. M. Porritt Build. Res. Inf., 45, 118, (2017).

[3] IEATransition to Sustainable Buildings. (2013)

[4] B. W. Olesen, ASHRAE J.54, 44-52, (2012).

[5] O. B. Kazanci, PhD Thesis DTU, (2016).

[6] H. Akeiber ,Renew. Sustain. Energy Rev., 60, 1470-1497, (2016).

[7] M. Koschenz and B. Lehmann Energy Build., vol. 36 567-578, (2004).

[8] F. Bourdakis, Eleftherios Kazanci, ASHRAE Annual Conference, 2016.

[9] L. Flemming Nielsen, E. Bourdakis, O.B. Kazanci, and B.W. Olesen, ASHRAE Winter Conference, (2018).

[10] H. Farhan, E. Bourdakis, B. W. Olesen, C. Stefansen, and O. B. Kazanci, ASHRAE Winter Conference, (2018).

[11] F. Kuznik, D. David, K. Johannes, and J. J. Roux, Renew. Sustain. Energy Rev.15,379-391 (2011)

[12] E. Fabrizio, S. P. Corgnati, F. Causone, and M. Filippi, HVAC\&R Res. 37-41, (2012).

[13] Wisconsin Madison, Universisty of (2018). TRNSYS: A transient systems simulationprogram.url:http://sel.me.wisc.edu/ trnsys/. (accessed: 06.06.2018).".

[14] O. B. Kazanci, D. Khovalyg, and B. W. Olesen, Final Report, DTU (2017).

[15] CEN, "EN 16798-1, (2016).

[16] Danish building regulations (2015).

[17] J. Kolarik, J. Toftum, B. W. Olesen, and K. L. Jensen, Energy Build. 43, 2988-2997, (2011).

[18] Rubitherm R24. www.rubitherm.eu/media/products/datasheets (Accessed 03/12/2018).

[19] Dentel, (2013).TRNSYS TYPE 399: http://www.trnsys.de/download/de/ts type 3 99 en.pdf. (accessed: 01.05.2018).

[20] C. Stetiu, Energy Build.,30, no. 2, pp. 127-138, (1999).

[21] H. Weinläder, F. Klinker, and M. Yasin, Energy Build., 156, pp. 70-77, (2017).

[22] B. Delcroix, M. Kummert, and A. Daoud, Build. Perform. Simul.10,422-437, (2017). 